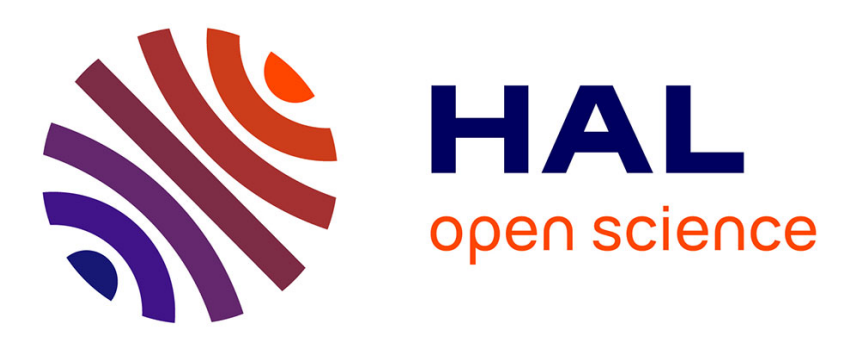

\title{
Optical losses characterization in channel waveguide through the photodeflection method
}

M. Bertolotti, G. Liakhou, R. Li Voti, A. Matera, C. Sibilia, M. Valentino

\section{To cite this version:}

M. Bertolotti, G. Liakhou, R. Li Voti, A. Matera, C. Sibilia, et al.. Optical losses characterization in channel waveguide through the photodeflection method. Journal de Physique IV Proceedings, 1994, 04 (C7), pp.C7-647-C7-650. 10.1051/jp4:19947153 . jpa-00253212

\section{HAL Id: jpa-00253212 https://hal.science/jpa-00253212}

Submitted on 1 Jan 1994

HAL is a multi-disciplinary open access archive for the deposit and dissemination of scientific research documents, whether they are published or not. The documents may come from teaching and research institutions in France or abroad, or from public or private research centers.
L'archive ouverte pluridisciplinaire HAL, est destinée au dépôt et à la diffusion de documents scientifiques de niveau recherche, publiés ou non, émanant des établissements d'enseignement et de recherche français ou étrangers, des laboratoires publics ou privés. 


\title{
Optical losses characterization in channel waveguide through the photodeflection method
}

\author{
M. Bertolotti, G. Liakhou*, R. Li Voti, A. Matera, C. Sibilia and M. Valentino \\ Dipartimento di Energetica, Università di Roma "La Sapienza", Via Scarpa 16, 00161 Roma, Italy \\ * Technical University of Moldova, Shtephan Cel Mare, 277012 Kishinev, Moldova
}

\begin{abstract}
The photodeflection method applied to the propagation losses characterization in channel waveguides is discussed using two different set-up configurations. 3-D and 1-D models are presented in order to calculate the photodeflection angle. The effects on the measurement of any set-up misalignment are studied. Different ways for determining the propagation losses are shown. Comparison between theoretical and experimental results for $\mathrm{Ti}: \mathrm{LiNbO}_{3}$ and a glass channel waveguide is also reported.
\end{abstract}

\section{INTRODUCTION}

The characterization of propagation losses in optical waveguides is a basic element to understand the physical processes which take place in the waveguide (i.e. absorption, scattering). The main idea, developed in the past by several techniques, is to calculate the propagation losses starting from the decay, in the direction of propagation, of any signal (thermal, optical, electrical) proportional to the guided light intensity (sliding prism ${ }^{1}$, pyroelectric ${ }^{2}$ and out of plane scattered light ${ }^{3}$ methods). Others techniques allow to estimate losses by measuring the quantity of heat generated in the sample (calorimetric ${ }^{4}$ method) or by measuring the width of the fringes of the optical resonator ${ }^{5.7}$ obtained polishing the waveguide endfaces. Recently a new method based on photodeflection effect (P.D.) has been proposed and used ${ }^{8}$. In general the P.D. technique analyzes the deflection of a test laser beam (probe) from its originary trajectory traveling in a medium with a thermally induced refractive index gradient ${ }^{9}$. For both planar and channel waveguides (see fig. 1) the refractive index gradient is due to the thermal gradient produced when the guided light, which is a prism or an endfire coupled time modulated pump laser beam, is absorbed during the propagation. Compared with the previous techniques, P.D. presents several advantages being contactless, independent on the optical coupling system and applicable to a wide range of both planar and channel waveguides with different geometry (buried channel, raised or embedded strip, rib or ridge guide) and materials. In the present paper several basic aspects are treated.Experimental results are reported.

\section{THEORY}

The deflection angle of a probe ray is given by the well known photodeflection formula

$$
\vec{\Phi}=\int_{\text {path }} \frac{\nabla_{\mathrm{t}} \mathrm{n}}{n} \mathrm{ds}=\int_{\text {path }} \frac{1}{\mathrm{n}} \frac{\partial \mathrm{n}}{\partial T} \nabla_{\mathrm{t}} \mathrm{T} \mathrm{ds}=\frac{1}{\mathrm{n}} \frac{\partial \mathrm{n}}{\partial T} \nabla_{\mathrm{t}} \int_{\text {path }} \mathrm{Tds}
$$




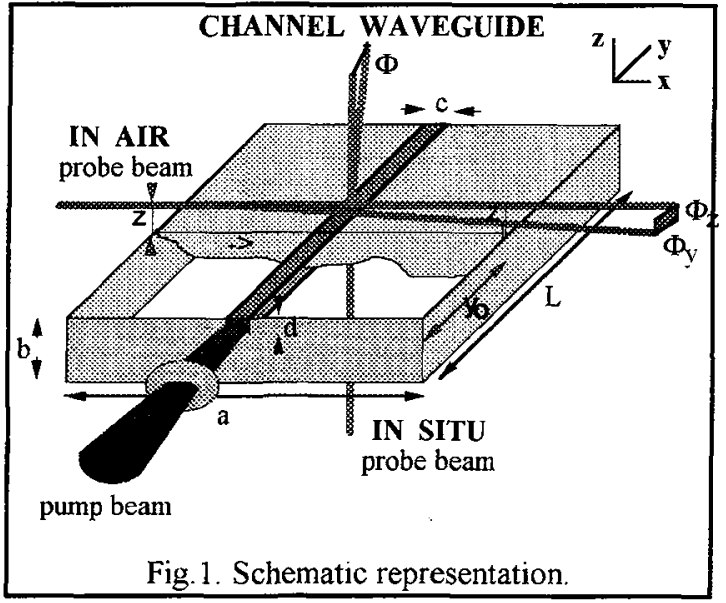

where $\mathrm{T}, \mathrm{n}, \mathrm{s}, \frac{\partial \mathrm{n}}{\partial \mathrm{T}}$ and $\nabla_{\mathrm{t}}$ denote the temperature rise, the refractive index, the probe path coordinate, the optothermal parameter and the gradient transverse to the ray path, respectively.

Depending on the probe beam path, two different transverse configurations can be distinguished and used (see Fig. 1). The probe beam travels, in both paths, perpendicular to the channel direction, impinging finally on a position sensor connected to a lock-in amplifier.In any case in the configuration in air, the probe skims through the layer of air close to the sample. Sometimes, if the sample has a low surface roughness, a stronger signal could be experimentally obtained by bouncing with a small

tilt angle the probe laser beam near the channel zone and by measuring the deflection angle of the reflected beam. The configuration in air is usually applied when a physical contactless detection system is needed (photorefractive or probe absorbing waveguides). The deflection angle $\bar{\Phi}$ has two components as usual: in the general case the component directed along the $z$ axis $\Phi_{\mathrm{Z}}$ is larger than the one along the propagation direction $\Phi_{y}$. In the case of low propagation loss waveguide, because of the low value of the air's optothermal parameter with respect to that of a solid sample, a configuration in situ is more suitable in order to measure a stronger signal. The probe beam is now focused on the channel waveguide, crossing the whole sample. In this configuration the deflection angle has only a component along the channel direction. In order to provide quantitatively an expression for the deflection angle, a theoretical model for the temperature distribution is needed. In general the 3-D solution of the second order differential Fourier equation cannot be given in a closed form due to the particular geometry of the boundary (see fig. 1). Numerical methods (FDM) or Schwarz-Christoffel transformation allows one to determine the exact solution. The Fourier Transformation Method provides an handy and accurate approximation which gives for both in situ and in air $\Phi_{y}$ the expressions

$$
\Phi_{y, \frac{a i r}{\text { sample }}}=\left(-\frac{1}{\mathrm{n}} \frac{\hat{c} \mathrm{n}}{\partial T}\right)_{\frac{\text { air }}{\text { sample }}} \frac{2 \alpha P^{\alpha}}{k_{1}} \int_{0}^{\alpha} \gamma_{\frac{\alpha i r}{\text { sample }}}\left[\frac{\alpha e^{-\alpha y}}{\beta_{c h}^{2}-\alpha^{2}}-\frac{k_{a i r} \beta_{a i r}+\alpha k_{c h}}{k_{\text {air }} \beta_{a i r}+k_{c h} \beta_{c h}} \frac{\beta_{c h} e^{-\beta_{c h} y}}{\beta_{c h}^{2}-\alpha^{2}}\right] d \delta, \gamma_{\substack{\xi=d \\ \xi=c}}=\frac{\sin (\delta \xi)}{\delta \xi\left(1-\left(\frac{\delta \xi}{\pi m}\right)^{2}\right)}
$$

being $\beta_{c h \text { air }}=\sqrt{\delta^{2}+\frac{j \omega}{D_{\text {ch/air }}}}$, where $\mathrm{P}, \mathrm{k}_{\mathrm{ch} / \mathrm{air}}, \mathrm{D}_{\mathrm{ch} / \mathrm{air}}, \omega, \alpha, \delta, \mathrm{m}$ and $\mathrm{p}$ denote the input power, the thermal conductivity and diffusivity of both channel waveguide and air, the chopper angular frequency the propagation losses coefficient, the spatial frequency and the mode indices of the guided light which has been modeled with Marcatili method. If we analyze $\Phi_{y}$ as a function of the channel direction (y) Eq.2 gives the same behavior found for a planar waveguide ( $1 \mathrm{D}$ model)

$$
\Phi \times \frac{\left(\alpha \ell_{w g}\right)^{2}}{2 i-\left(\alpha \ell_{w g}\right)^{2}}\left\{\exp [-\alpha l]-\frac{\alpha f_{w g}+e(1+i)}{(1+e) \alpha \ell_{w g}} \exp \left[-\frac{1+i}{l_{w g}} y\right]\right\}
$$

where $\ell_{\text {air }: w g}=\sqrt{\frac{2 D_{a i r / w g}}{\omega}}, e=\frac{e_{\text {air }}}{e_{w g}}=\sqrt{\frac{k_{a i r}(\rho c)_{a i r}}{k_{w g}(\rho c)_{w g}}}=\frac{k_{a i r}}{k_{w g}} \sqrt{\frac{D_{w g}}{D_{\text {air }}}}=\frac{k_{a i r} \ell_{w g}}{k_{w g} \ell_{a i r}}, \rho$ and $c$ are the thermal 
diffusion length, the thermal effusivity ratio, the density, and the heat capacity respectively. The deflection angle depends on two exponential terms which have different decay lengths connected respectively with thermal diffusion and optical absorption. However in usual cases, for low loss channel waveguides, the thermal diffusion exponential term has importance only for the first few microns $\left(y<<\ell_{\text {ch }}\right.$ ), being negligible for longer distances from the input edge. A way to calculate the propagation losses is therefore suggested by studying the deflection angle as a function of distance $y$ of the probe beam from the waveguide edge. In other words, starting away from the edge, the amplitude of the photodeflection signal has only the exponential behavior due to absorption processes, from which one obtain the propagation loss coefficient (see Figs 2). However this method is not useful for loss coefficients less than $1 \mathrm{~dB} / \mathrm{cm}$. In fact in order to minimize the noise one should perform measurements for very large values of $y$, sometimes larger than the available length of channel. A recurring problem in air configuration scanning is the set-up misalignment. The effect of a small tilt angle between the surface and the probe scanning line could be very important especially for small $\alpha$, because an unknown slope change in the channel direction is produced in both amplitude and phase of the deflection signal. The attenuation $\alpha^{\prime}$ and the phase $\phi$ and the phase drift $\mathrm{d} \phi / \mathrm{dt}$ of the deflection signal depend on the tilt angle $\theta$ as

$$
\alpha^{\prime}=\alpha+\frac{\operatorname{tg}(\theta)}{\sqrt{2 D_{a i r}}} \sqrt{\omega}, \quad \varphi=\varphi_{0}+\frac{\operatorname{tg}(\theta)}{\sqrt{2 D_{a i r}}} \sqrt{\omega} \cdot y, \quad \frac{d \varphi}{d y}=\frac{\operatorname{tg}(\theta)}{\sqrt{2 D_{a i r}}} \sqrt{\omega}
$$

An elegant way to obtain the right $\alpha$ is measuring attenuation for different values of the chopper frequency. Plotting $\alpha^{\prime}$ as a function of the frequency square root a straight line is obtained from which both $\alpha$ and $\theta$ are calculated. Another way is given by the comparison (difference) beetween $\alpha^{\prime}$ and the phase drift. To avoid this problem another way is suggested by the analysis of the deflection amplitude of the component along the channel direction $\left(\Phi_{\mathrm{v}}\right)$ in the first few microns.

In the analysis for short distance, the diffusion exponential term can't be neglected with respect to the absorption term. Considering however the phase of the two terms it is possible to find some length $y_{\min }$ for which the two exponentials have opposite sign so that a minimum in the deflection signal is obtained. With the help of a computer one may find the distance $y_{\min }$, which depends mainly on the effusivity ratio and on the loss coefficient and if $\alpha t_{\mathrm{ch}}>\mathrm{e}$. the empirical relation is found

$$
\alpha y_{\min }=\ln (1+e) \approx e \quad \text { from which } \alpha=\frac{e}{y_{\min }} .
$$

The minimum is directly connected to the existence of a maximum in temperature inside the waveguide. Due to the low value of the effusivity ratio in the general case of a solid sample, the existence condition $\alpha \ell_{\mathrm{ch}} \gg \mathrm{e}$ is in many cases verified.

\section{EXPERIMENTAL RESULTS}

The channel waveguide which has been used to test the first method by measuring the exponential decay of the deflection signal, was a glass substrate with six channels $3 \mu \mathrm{m}$ wide, obtained by ion exchange. The refractive index of substrate is 1.55 with an increase in each channel of about 0.005 . In figure $2 \mathrm{a}$ the logarithm of amplitude of $\Phi_{y}$ vs y $(\mu \mathrm{m})$ is shown for different frequencies. Note that starting from a certain distance, the experimental curves have a linear behavior. The different slopes $\left(\alpha^{\prime}\right)$ are reported in the table and plotted in figure $2 \mathrm{~b}$ as a function of frequency square root. A tilt angle of about $25^{\circ}$ produced different values as a function of frequency. In columns 3 and 4 of the table the phase drift and the difference with $\alpha^{\prime}$ are reported. The propagation loss obtained by using Eq. 4 is $\alpha \approx 9 \mathrm{~cm}^{-1}( \pm 10 \%)$. The channel waveguide used to check the minimum method, was a $\mathrm{Ti}: \mathrm{LiNbO}_{3}$. The value of the effusivity ratio at room temperature is about $\mathrm{e} \approx 0.0012$. The measurement reported in fig. 3 was made at a chopper frequency $\mathrm{f}=18 \mathrm{~Hz}$ so that the thermal length is about $\ell_{\mathrm{ch}} \approx 130 \mu \mathrm{m}$, which just assures the condition to have a minimum. In fig. 3 both theory and experimental data are shown for the normalized deflection signal in the in situ configuration. The theoretical curves take into account three different values of the probe 
beam size $\mathrm{e}^{10}$. The fit is in good agreement with eq. 5 giving a value of about $\alpha \approx 0.25 \mathrm{~cm}^{-1}( \pm 10 \%)$.

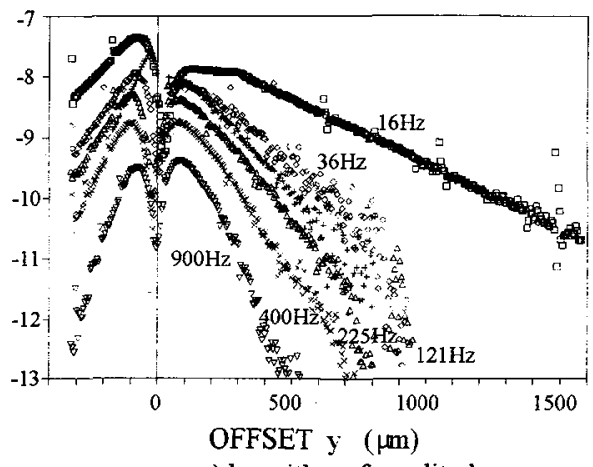

a) logarithm of amplitude

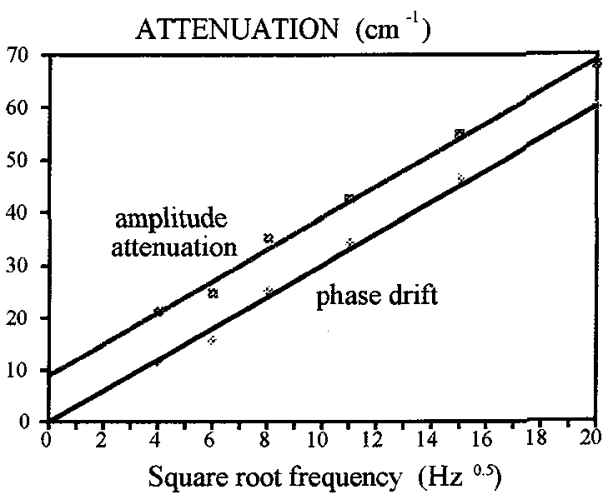

b) measured losses

Figs.2: glass waveguide: the chopper frequencies are shown, the measured loss is $\alpha \approx 9 \mathrm{~cm}^{-1}$.

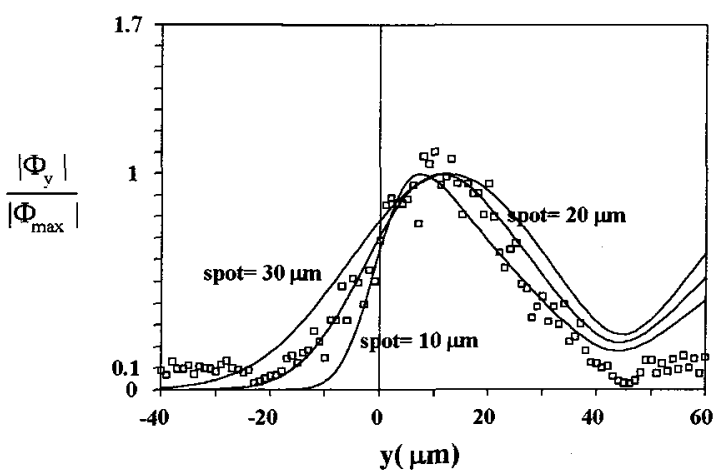

TABLE

\begin{tabular}{|c|c|c|c|}
\hline f (Hz) & $\alpha^{\prime}(1 / \mathrm{cm})$ & $\begin{array}{c}\text { phase drift } \\
(1 / \mathrm{cm})\end{array}$ & $\begin{array}{c}\text { difference } \\
(1 / \mathrm{cm})\end{array}$ \\
\hline 16 & $21.2 \pm 0.14$ & $11.7 \pm 0.14$ & 9.5 \\
\hline 36 & $24.7 \pm 0.5$ & $15.6 \pm 0.5$ & 9.1 \\
\hline 64 & $35 \pm 1$ & $25.4 \pm 1$ & 9.6 \\
\hline 121 & $42.6 \pm 1.4$ & $34.2 \pm 0.6$ & 8.4 \\
\hline 225 & $54.8 \pm 0.9$ & $46.5 \pm 0.7$ & 8.3 \\
\hline 400 & $68 \pm 1$ & $60 \pm 1$ & 8 \\
\hline 900 & $80 \pm 3$ & $72 \pm 3$ & 8 \\
\hline
\end{tabular}

Fig.3: the amplitude of the deflection angle for a waveguide of $\mathrm{Ti}: \mathrm{LiNbO}_{3}$ : $\square$ experimental points. cont. line numerical results for different beam sizes $(10,20,30 \mu \mathrm{m})$. The frequency is $\mathrm{f}=18 \mathrm{~Hz}$ and the measured loss is $\alpha \approx 0.25 \mathrm{~cm}^{-1}$

\section{REFERENCES}

[1] H.P.Weber, F.A.Dunn, W.W.Leibolt:- Appl.Optics 12 (1973) 755-760.

[2] A.M.Glass, I.P. Kaminov, A.A.Aliman, D.H.Olson- Appl.Opt. 19 (1980) 276-282.

[3] Y.Okamura, S.Yoshinaka, S. Yamamoto- Appl.Opt. 22(1983) 3892 - 3900.

[4] K.H.Heagele, R.Ulrich:- Opt.Lett. 4 (1980) 60-63.

[5] I.P.Kaminov, L.W.Stulz:-Appl.Phys.Lett. 33 (1978) 62-65.

[6] R.Reganer, W.Sohler-Appl.Phys.B 36 (1985)143-148.

[7] S.V.Bessonova, K.S. Buritskii, V.A.Chenykh, E.A.Shcherbakov- Sov.J. Quant. El. 19 (1989) 559-565

[8] R.K.Hickeneil, D.R.Larson, R.J.Phelan, L.Larson - Appl.Opt. 27 (1988) 1637 -1645.

[9] W.B.Jackson, N.M.Amer, A.C.Boccara- Appl.Opt. 20, (1981)1333 -1345.

[10] M.Bertolotti, L.Fabbri, E.Fazio, R.Li Voti, C.Sibilia, G.Leakhou, A.Ferrari- J.Appl.Phys. 69 (1991)3421-3426. 